2015

\title{
Adapting to a New Core Curriculum at Hood College: From Computation to Quantitative Literacy
}

Betty Mayfield

Hood College, mayfield@hood.edu

Jill B. Dunham

Hood College, jillbd@gmail.com

\section{Recommended Citation}

Mayfield, Betty, and Jill B. Dunham. "Adapting to a New Core Curriculum at Hood College: From Computation to Quantitative Literacy." Numeracy 8, Iss. 2 (2015): Article 8. DOI: http://dx.doi.org/10.5038/ 1936-4660.8.2.8 


\title{
Adapting to a New Core Curriculum at Hood College: From Computation to Quantitative Literacy
}

\begin{abstract}
Our institution, a small, private liberal arts college, recently revised its core curriculum. In the Department of Mathematics, we took this opportunity to formally introduce Quantitative Literacy into the language and the reality of the academic requirements for all students. We developed a list of characteristics that we thought all QL courses should exhibit, no matter in which department they are taught. We agreed on a short list of learning outcomes for students who complete those courses. Then we conducted a preliminary assessment of those two attributes: the fidelity of QL-labeled courses to our list of desired characteristics, and our students' success in meeting the learning objectives. We also performed an attitudes survey in two courses, measuring students' attitudes towards mathematics before and after completing a QL course. In the process we have had valuable conversations with full- and part-time faculty, and we have been led to re-examine the role of adjunct faculty in our department. In this paper we list our course characteristics and include one instructor's description of how she ensured that her QL course exhibited many of those traits. We include examples of student work illustrating how they met the learning objectives, and we report on the results of our attitudes survey. Much remains to be done; we describe our preliminary conclusions and plans for the future.
\end{abstract}

\section{Keywords}

quantitative literacy, assessment, core curriculum

\section{Creative Commons License}

\section{c) (i) (8)}

This work is licensed under a Creative Commons Attribution-Noncommercial 4.0 License

\section{Cover Page Footnote}

Betty Mayfield is professor of mathematics at Hood College. She has taught a wide range of courses at the college, and has served the past fifteen years as department chair and assessment coordinator. She became interested in QL at an MAA PREP workshop at the Sleeping Lady Mountain Resort in 2004.

Jill Bigley Dunham is an assistant professor of mathematics at Chapman University in Orange, California. She has taught a wide variety of courses including The Mathematics of Daily Life, calculus, modeling and simulation, and discrete mathematics. While at Hood College, Jill developed a course, The Mathematics of Games and Sports, which is part of the quantitative literacy curriculum discussed in the paper. 


\section{A New Core Curriculum}

In the fall of 2013, the faculty at Hood College, a small, private liberal arts college, voted to adopt a new core curriculum for all students, beginning with those who would enter the following fall. There were many factors that led us to make such a move - changes in teaching loads, and in the number of credits courses carry; an evaluation of the current general curriculum; and a desire to offer students a liberal arts education that prepares them for life after college. In the Department of Mathematics, we took this opportunity to look carefully at the "math" requirement in the core curriculum and make the change we had long wanted to make: replacing the Computation section of the Core with a true Quantitative Literacy (QL) requirement. We will use the term QL in the sense of "comfort, competency, and 'habit of mind' in working with numerical data," as described on the National Numeracy Network website (2013). ${ }^{1}$

\section{From "Computation" to "Quantitative Literacy"}

For as long as anyone can remember, there has been a Computation section of our college's Core Curriculum, along with Writing, Foreign Language, and Physical Education. Its goal was described succinctly in the Catalog:

Students will be able to solve basic mathematical problems and demonstrate some ability to interpret and present numerical data.

While that description does have something of a QL feel to it, and many of the mathematics courses that satisfied the Computation requirement were designed as QL courses, we wanted to be more explicit about the goals of this part of the Core in its new incarnation, and we wanted to introduce QL language into the Catalog. The new requirement is called Quantitative Literacy, and the Catalog description now says:

Quantitative literacy (QL) is a habit of mind. It involves using elementary mathematical tools to interpret and manipulate quantitative data arising in a variety of contexts. It is marked by computational fluency, and by competence and comfort in working with numerical data. Those who are quantitatively literate can create arguments supported by data and can communicate those arguments in many ways - using tables, graphs, mathematical expressions, and words.

A course that satisfies the QL section of the Core Curriculum should have as its main focus the use of mathematics to solve real-world problems. In those courses, using data and appropriate technology, students will collaborate to solve multi-step problems and effectively communicate their reasoning to others.

\footnotetext{
${ }^{1}$ http://serc.carleton.edu/nnn/resources/index.html
} 
We relied upon previous work and definitions provided by Steen $(2001,2004)$, Gillman (2011), and the National Numeracy Network (2013) in crafting our new description.

\section{Implementation: QL Courses}

Courses in several different academic departments satisfy the new requirement, so that students will, whenever possible, encounter quantitative literacy topics in the context of subjects that interest them. The current list of QL courses follows. (See Appendix A for course descriptions.)

\section{Courses designed as general education courses}

MATH 111 Mathematics Everywhere

MATH 111A The Mathematics of Daily Life

MATH 111B The Mathematics of Democracy

MATH 111G The Mathematics of Games and Sports

\section{Statistics courses}

MATH 112 Applied Statistics

MATH 112W Workshop Statistics

MATH 213 Statistical Concepts and Methods

ECON/MANAGEMENT 212 Statistics for Economics and Management

PSYCHOLOGY 211 Elementary Statistics

SOCIOLOGY 261 Quantitative Methods for the Social Sciences

\section{Calculus}

MATH 201 Workshop Calculus I

\section{Assessment}

We knew that our college would ultimately want to assess the effectiveness of our new core curriculum in general, and we wanted to begin to assess the new QL section in particular. With a fairly wide range of courses satisfying this requirement, we sought to design assessment instruments that could be used across courses and departments to determine how well students were meeting the goals of the core curriculum, no matter which courses they chose from the QL list. In this paper, the term "assessment" refers to program assessment - evaluating the effectiveness of 
the courses and instruction, rather than the evaluation of individual students' performances.

Our department has a history of interest in and commitment to the evaluation of student learning, stemming from our participation in a series of SAUM (Strengthening Assessment of Undergraduate Mathematics) workshops led by the Mathematical Association of America (MAA) over a two-year period from 2004 to 2006 (see Steen 2006). As a result of that experience, we have developed a fairly robust assessment plan for our mathematics major; we wanted to expand it to include courses in general education, focusing particularly on quantitative literacy.

We also have a long-standing commitment to the use of "best practices" in pedagogy: in our calculus courses and beyond, we emphasize student-centered, inquiry-based learning, collaboration and group work, the use of technology, and reading and writing about mathematics. ${ }^{2}$ And we are interested in how those pedagogical methods affect student attitudes about mathematics (Strand and Mayfield 2002). With the adoption of the new core curriculum, we were especially interested in the attitudes of possibly math-phobic non-majors and whether or not a carefully crafted QL course, using many of the methods described above, could change those attitudes.

Gold (2006: 30-31) describes the particular assessment cycle for QL courses:

- Examine goals and learning objectives. "What do we want students to get out of this course?"

- Move from goals to measurable learning objectives. Make the goals concrete. How can we tell when students have met them?

- Share goals and objectives with all constituents. These include students as well as full-time and part-time faculty.

- Choose appropriate assessment mechanisms. Formative or summative? Timed tests or homework assignments? A survey of attitudes?

- Complete the cycle: Use the data. What changes do we need to make in the program as a result of what we have learned?

We wanted to make sure that we followed the steps of this cycle in assessing our QL program. We ultimately decided to evaluate courses' outcomes in three different ways:

- How did the courses satisfy our definition of a QL course?

\footnotetext{
${ }^{2}$ For a description of typical reformed teaching practices, see "What is reformed teaching?" http://serc.carleton.edu/NAGTWorkshops/certop/reformed teaching.html (last accessed 24 May 2014).
} 
- How did students demonstrate their understanding and mastery of the general goals we set for QL courses?

- Did students' attitudes about mathematics change during a course?

\section{How to recognize a QL course}

It is not difficult to find lists of desirable QL outcomes of a college education. For instance, the MAA Subcommittee on Quantitative Literacy Requirements of the Committee on the Undergraduate Program in Mathematics (Sons et al. 1996, p. 2) made several general recommendations, including:

- Colleges and universities should treat quantitative literacy as a thoroughly legitimate and even necessary goal for baccalaureate graduates;

- Colleges and universities should expect every college graduate to be able to apply simple mathematical methods to the solution of real world problems.

In particular, they recommend (p. 9) that

A quantitatively literate college graduate should be able to:

- Interpret mathematical models such as formulas, graphs, tables, and schematics, and draw inferences from them.

- Represent mathematical information symbolically, visually, numerically and verbally.

- Use arithmetical, algebraic, geometric and statistical methods to solve problems.

- Estimate and check answers to mathematical problems in order to determine reasonableness, identify alternatives, and select optimal results.

- Recognize that mathematical and statistical methods have limits.

In framing our new QL requirement, in describing it to our colleagues, and in determining which courses would meet it, we brainstormed over the course of many Mathematics Department meetings and came up with a list of desirable characteristics for a QL course, all based on the description of quantitative literacy we had prepared for the Catalog and on the recommendations above. The complete list may be found in Appendix B; it includes competencies like problem-solving, working with data, and communicating about quantitative issues, but also pedagogical touchstones like collaborative learning, active learning, and using multiple forms of assessment. 


\section{Goals for a $Q L$ course}

We agreed on the following general outcomes for a course in this section of the Core Curriculum. In most cases their dependence on the lists in the previous section is apparent.

Students who successfully complete a QL course should be able to

- Demonstrate computational fluency. ${ }^{3}$

- Understand and interpret data presented in a variety of formats, and convert from one format to another.

- Draw conclusions based on numerical data and assess the limitations of those conclusions.

- Evaluate quantitative arguments in a variety of settings.

- Communicate their understanding of the usefulness of mathematics.

\section{Changes in attitudes?}

We realized that, although we had not voiced a change in attitude as a desired outcome in our list, we also hoped that, by successfully completing a QL course, students would recognize the importance of quantitative fluency and ideally develop more positive attitudes toward math.

\section{Preliminary Results}

To prepare for the official implementation of the new QL requirement in the fall of 2014, we spent the 2013-2014 academic year designing and testing assessment instruments. In a preliminary pilot program in the fall semester, we began with the courses taught in our department, specifically MATH 111 Mathematics Everywhere and MATH 112 Applied Statistics.

\section{Designing and assessing QL courses}

One measure of the QL "fit" of a particular course is its attention to the characteristics listed in Appendix B: How to Recognize a QL Course. At the beginning of the semester, we gave the instructor of each course the list of desirable characteristics found in Appendix B. At the end of the semester, we asked him or her to comment on how the course addressed the items on this list. All four instructors responded, interpreting our request in different ways. Some answers

\footnotetext{
${ }^{3}$ This term gained popularity with the publication of the 2000 NCTM Standards (National Council of Teachers of Mathematics 2000). On an associated web site, the term is defined as "having efficient, flexible and accurate methods for computing."
} 
were brief ("Yes, we used many of these strategies"); one instructor addressed the Goals for a QL Course instead (see the previous section). But all of the instructors also provided us with examples of assignments and student work, which was very helpful to us. One instructor really took our request to heart; here are some excerpts from the especially extensive response from this instructor regarding MATH 111A The Mathematics of Daily Life:

- Problem Solving. The first two topics in Math $111 \mathrm{~A}$ are Euler circuits and Hamiltonian circuits, where students determine most efficient routes for mail carriers, airlines, etc. In the personal finance unit students determine how much mortgage they can afford and how much they need to save per month to accrue a down payment.

- Working with Data. We do a complete unit on one-variable and two-variable statistics. We develop the skills necessary to analyze the statistics by hand and with Excel. Interpreting graphs, 5-number summaries, stem plots, etc. are emphasized.

- Using (and Knowing When to Use) Appropriate Technology. About a third of the course involves using Excel. We do three labs and a project using Excel to manage and analyze personal finances. We use Excel to present and analyze one variable and two variable statistics, as well.

- Active Learning and Engagement. The class format includes very little lecture. Much more time is spent on well-designed worksheets and labs that introduce and develop the subject matter. Students are encouraged to talk to each other as they work through the worksheets and material. At the same time they can question and seek reinforcement from the instructor. Often the class summary is an exit slip demonstrating mastery of the day's topic.

From her responses about how this course is taught and what students learn in it, we are convinced that MATH 111A does indeed include the characteristics we expect to find in a QL course. We also realized how much work it was to write out responses to our entire list. Many of the instructors for the QL courses are adjunct faculty, and while they are eager to help, and we value their role in this process, we do not want to burden them unnecessarily with work associated with assessment. When we ask for information, we should be clear about how much and what kind of a response we want, and we should make responding to our request straightforward and fairly easy to do. ${ }^{4}$

\section{Evidence that courses are meeting our goals}

In addition to examining how the courses met our objectives, we were interested in finding out how the students in those courses demonstrated their understanding

\footnotetext{
${ }^{4}$ As Gold (2006, p. 30) points out, "In larger institutions there are typically several sections of these introductory courses each semester, often taught by adjunct faculty or graduate students." We find that to be true even at a relatively small institution. As the percentage of college courses taught by adjunct faculty grows, it is natural for those faculty to be concentrated in lower-level courses, while the tenure-track faculty tend to teach the more-desirable upper-level courses.
} 
of the course content, and in particular of the QL knowledge and skills we hoped they were developing. We gave those same four instructors a list of the learning outcomes for QL courses - in fact, they had been instrumental in developing them - and asked them to give us examples of student work that illustrated students' mastery of those objectives. The following examples may be helpful to instructors in similar courses.

\section{Example from MATH 111 Math of Daily Life. Buying a House}

In the Buying a House assignment, students explore real data, picking out a house, calculating the down payment and mortgage needed, along with their future salaries and savings plan. The students write up their findings in a letter and use Excel to make the calculations. This project addresses four of the five goals: computational fluency, understanding and interpreting data, drawing conclusions, and communicating results. Figures 1 and 2 show a sample student submission.

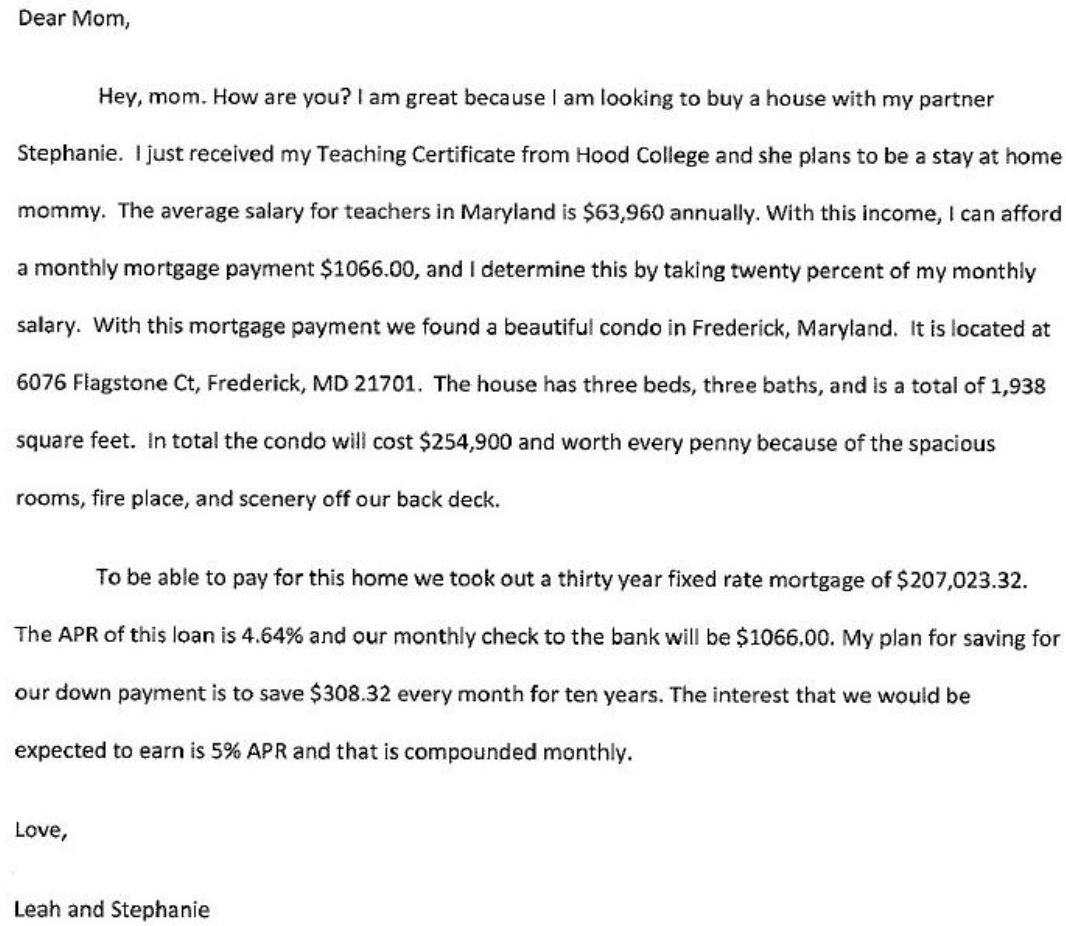

Figure 1. A letter explaining the details of the house project. 


\begin{tabular}{|c|c|c|c|c|c|}
\hline \multicolumn{2}{|c|}{ Start Balance } & Interest & Payment & End Balance & \multirow{7}{*}{$\begin{array}{l}\text { APR } \\
\text { Monthly }\end{array}$} \\
\hline 1 & $\$ 207,023.32$ & $\$ 800.15$ & $\$ 1,066.00$ & $\$ 206,757.46$ & \\
\hline 2 & $\$ 206,757.46$ & $\$ 799.12$ & $\$ 1,066.00$ & $\$ 206,490.58$ & \\
\hline 3 & $\$ 206,490.58$ & $\$ 798.09$ & $\$ 1,066.00$ & $\$ 206,222.67$ & \\
\hline 4 & $\$ 206,222.67$ & $\$ 797.05$ & $\$ 1,066.00$ & $\$ 205,953.72$ & \\
\hline 5 & $\$ 205,953.72$ & $\$ 796.01$ & $\$ 1,066.00$ & $\$ 205,683.73$ & \\
\hline 6 & $\$ 205,683.73$ & $\$ 794.97$ & $\$ 1,066.00$ & $\$ 205,412.70$ & \\
\hline 7 & $\$ 205,412.70$ & $\$ 793.92$ & $\$ 1,066.00$ & $\$ 205,140.62$ & \multirow{16}{*}{$\begin{array}{l}\text { a) Our annual salary is } \$ 63,960.00 \text {. Our annual salary multiplied } \\
\text { by four is } \$ 255,840.00 \text {. Our monthly salary is } \$ 5,330,00 \text {. And } \\
20 \% \text { of our monthly salary which is our monthly payment is } \\
\$ 1,066.00 \text { ( teacherportal.com) }\end{array}$} \\
\hline 8 & $\$ 205,140.62$ & $\$ 792.87$ & $\$ 1,066.00$ & $\$ 204,867.48$ & \\
\hline 9 & $\$ 204,867.48$ & $\$ 791.81$ & $\$ 1,066.00$ & $\$ 204,593.30$ & \\
\hline 10 & $\$ 204,593.30$ & $\$ 790.75$ & $\$ 1,066.00$ & $\$ 204,318.05$ & \\
\hline 11 & $\$ 204,318.05$ & $\$ 789.69$ & $\$ 1,066.00$ & $\$ 204,041.74$ & \\
\hline 12 & $\$ 204,041.74$ & $\$ 788.62$ & $\$ 1,066.00$ & $\$ 203,764.36$ & \\
\hline 13 & $\$ 203,764.36$ & $\$ 787.55$ & $\$ 1,066.00$ & $\$ 203,485.91$ & \\
\hline 14 & $\$ 203,485.91$ & $\$ 786.47$ & $\$ 1,066.00$ & $\$ 203,206.38$ & \\
\hline 15 & $\$ 203,206.38$ & $\$ 785.39$ & $\$ 1,066.00$ & $\$ 202,925.78$ & \\
\hline 16 & $\$ 202,925.78$ & $\$ 784.31$ & $\$ 1,066.00$ & $\$ 202,644.08$ & \\
\hline 17 & $\$ 202,644,08$ & $\$ 783.22$ & $\$ 1,066.00$ & $\$ 202,361.30$ & \\
\hline 18 & $\$ 202,361.30$ & $\$ 782.13$ & $\$ 1,066.00$ & $\$ 202,077.43$ & \\
\hline 19 & $\$ 202,077.43$ & $\$ 781.03$ & $\$ 1,066.00$ & $\$ 201,792.46$ & \\
\hline 20 & $\$ 201,792.46$ & $\$ 779.93$ & $\$ 1,066.00$ & $\$ 201,506.39$ & \\
\hline 21 & $\$ 201,506.39$ & $\$ 778.82$ & $\$ 1,066.00$ & $\$ 201,219.21$ & \\
\hline 22 & $\$ 201,219.21$ & $\$ 777.71$ & $\$ 1,066.00$ & $\$ 200,930.92$ & \\
\hline
\end{tabular}

Figure 2. A portion of the spreadsheet from the house project.

Students were graded both on their writing (10 points) and their use of a spreadsheet (10 points). During the fall semester of 2013, students in this course earned an average score of 17.44 out of 20 points (87.2\%) and 20 out of 25 students earned a grade of $80 \%$ or higher on this project. Four students earned a grade of D (between 12 and 14 points) and one failed with a total of 6 points. In a perfect world, for this assignment and others, our goal is for students to achieve at the $80 \%$ level consistently.

\section{Examples from MATH 111G, Math of Games and Sports}

\section{NFL Passer Rating Lab}

In the NFL Passer Rating assignment, students are given an Excel file with the basic structure for a table to calculate NFL Passer Rating. They are then asked to fill in the formulas based on the equations in the textbook and to fill in data from Internet research. They must interpret the results. Is the answer meaningful? Does it agree with reality? Passer rating is something that can be found on the Internet. Are there any surprising answers due to an error in the spreadsheet or some other reason?

This assignment addresses all five of our goals: computational fluency; understanding and interpreting data presented in a variety of formats and converting from one format to another; drawing conclusions based on numerical data and 
assessing the limitations of these conclusions; evaluating quantitative arguments in a variety of settings; and communicating an understanding of the usefulness of mathematics.

Figure 3 shows an example response, where a student made some errors, but was at least suspicious of the result. The figure reproduces the response verbatim, including the inventive spelling.

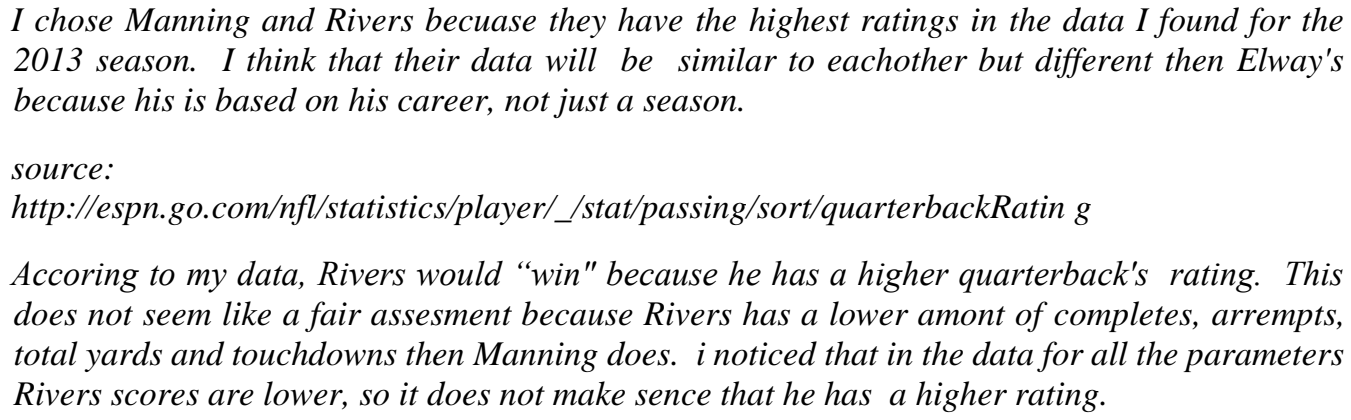

\begin{tabular}{l|r|l|l|l|l|l|l}
\hline \multicolumn{2}{l|}{ NFL Passer Ratings } & & & Names: & \\
\hline
\end{tabular}

Figure 3. A student response (above), and the framework provided for students in the NFL Passer Ratings lab.

Students were graded on their use of Excel to obtain correct numerical answers as well as their ability to interpret their results. In the fall semester of 2013, students averaged a score of 9.19 out of 10 points on this lab. Students who completed the assignment generally did very well: 19 of 21 students scored $80 \%$ or higher. The other two students did not finish the lab and earned only 5 points.

\section{Cracking the Scratch Lottery Code}

In the Scratch Lottery lab, we analyzed a set of real scratch tickets (\$1 tickets) along with the data available on the Maryland Lottery website. ${ }^{5}$ We calculated the expected value of the game and made a prediction of how many tickets would be winners. We came surprisingly close with our predictions, both in number of tickets and in average value for the sample of tickets we checked. The spreadsheet in Figure 4 was created from scratch by a student and demonstrates the process. An

${ }^{5}$ www.mdlottery.com (last accessed May 25, 2015) 
accompanying reading, "Cracking the Scratch Lottery Code" (Lehrer 2011) from Wired magazine described some deeper topics related to scratch tickets.

\begin{tabular}{|r|r|r|r|r|r|}
\hline prizes & total prizes & prob. of ind. payout & payout & summands & \\
\hline 2000 & 25 & $5.89424 \mathrm{E}-06$ & 1999 & 0.011782583 & \\
\hline 1000 & 36 & $8.4877 \mathrm{E}-06$ & 999 & 0.008479216 & \\
\hline 500 & 57 & $1.34389 \mathrm{E}-05$ & 499 & 0.006705993 & \\
\hline 100 & 584 & 0.000137689 & 99 & 0.013631252 & \\
\hline 50 & 1591 & 0.000375109 & 49 & 0.018380358 & \\
\hline 30 & 2877 & 0.000678309 & 29 & 0.01967096 & \\
\hline 15 & 5648 & 0.001331626 & 14 & 0.018642769 & \\
\hline 10 & 14354 & 0.003384236 & 9 & 0.030458124 & \\
\hline 5 & 98797 & 0.023293323 & 4 & 0.093173293 & \\
\hline 2 & 289287 & 0.068205063 & 1 & 0.068205063 & \\
\hline 1 & 390045 & 0.09196073 & 0 & & \\
\hline & 803301 & & & & \\
\hline & & & & & \\
\hline
\end{tabular}

Figure 4. Student-created worksheet to analyze the expected value of a scratch ticket

This lab touches on all five of our goals, including communicating understanding of the usefulness of mathematics through answering additional questions with this lab and on the reading.

In fall 2013, of the 16 students who submitted this lab, 12 scored $80 \%$ or higher; the other 4 scored at $70 \%$. The average score for these 16 students was 8.625 out of 10 points.

\section{Slope and Data in Different Formats}

This example is from the Math of Games final exam. Students were provided with Figures 5 and 6 and were asked to answer questions about them. Sample responses are shown in Figures 7 and 8. On the exam, these figures were numbered 3 and 4. 


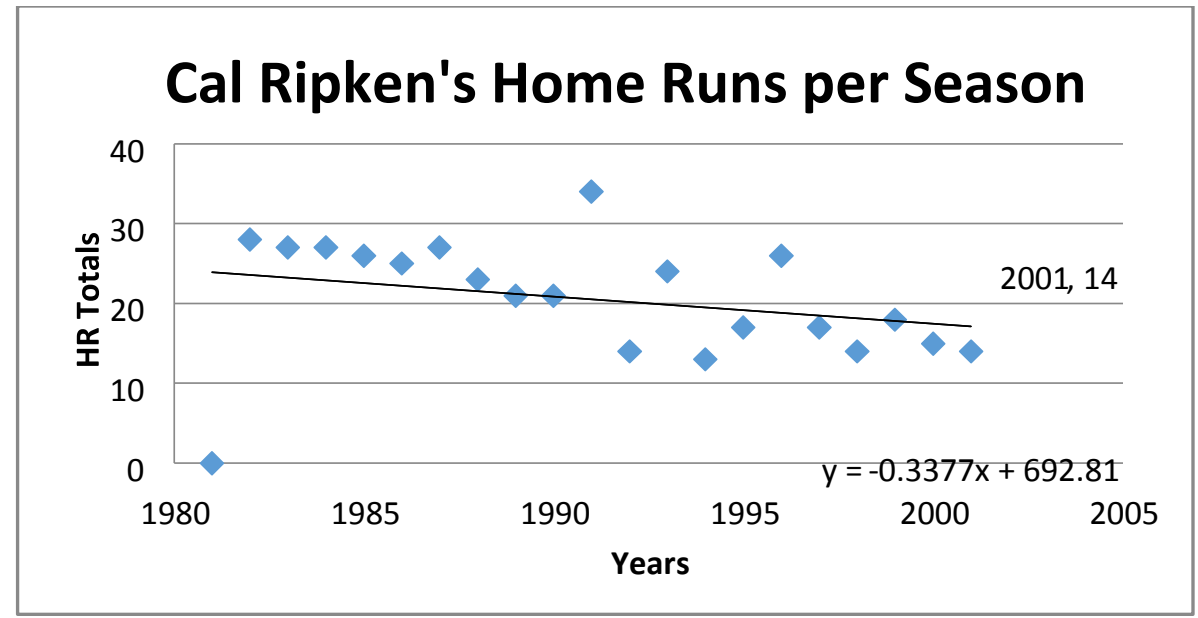

Figure 5. Graph given to students on final exam

\section{Cal Ripken's Home Runs per Season}

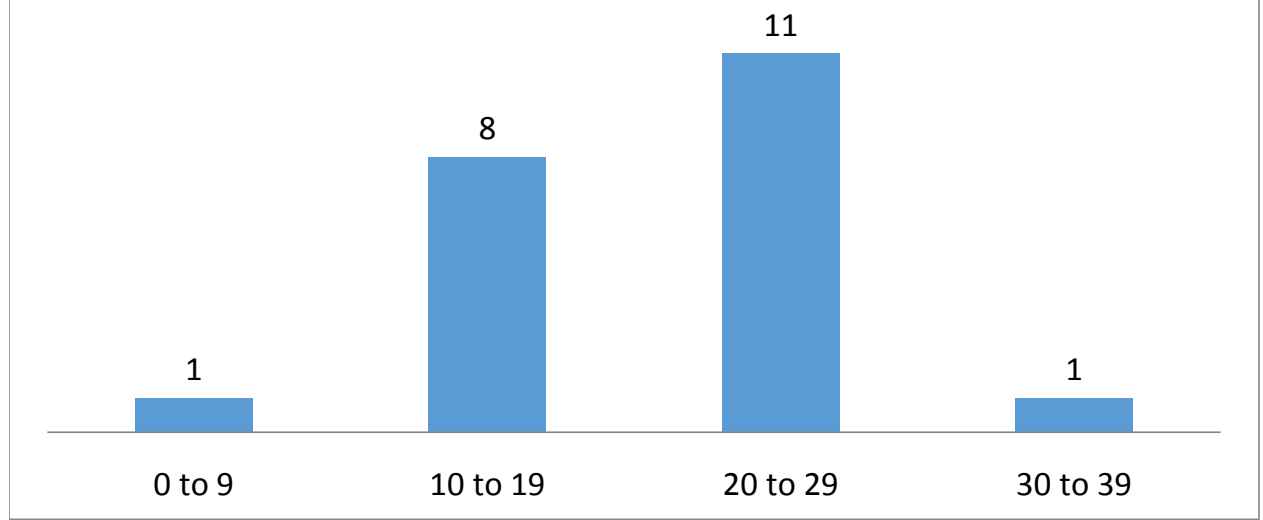

Figure 5. Histogram given to students on final exam

This question allows students to demonstrate mastery of two goals: understanding and interpreting data presented in a variety of formats, and assessing limitations of models. This 10-point question had four parts, where the students needed to provide short answers. There were no direct calculations to be made, and 
the students were not evaluated on their use of Standard English, but only on their demonstration of familiarity with the concepts.

In the fall semester of 2013, students averaged a score of about 8.3 out of 10 points on this question. Sixteen of 21 students scored $80 \%$ or higher; one student each earned $70 \%, 60 \%$, and 50\%; and two completely-lost students earned $20 \%$ on the problem. b),

The responses in Figure 7 come from a strong student, who wrote: (for

The important piece of information which is omitted from figure 4 is the years in which he hit those homeruns. Figure 3 shows his homerun totals over the course of his career."

and for (c),

The $m$ part of the formula represents the slope. It tells us that on average every season,

Cal Ripken's home run totals drops by about 0.3377 home runs.

b. The chart in figure 4 gives a nice aggregate view of the data, but what important piece of information is presented in figure 3 that is impossible to get from figure 4 ?

The importent pice of infermetion which is omites from

figure 4 is the yeors in which he hit there homesuas.

fiage 3 showes wis homerva tustels amer the course of his

coreas.

c. Figure 3 has a linear model superimposed on the data, along with a formula ( $y=$ etc.) Which part of the formula represents the slope of the linear model, and what does that number tell you about the data? The $m$ port of the focmulo rceresonth

the slope. It tells us that on averoge

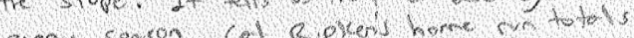
drops ly about 0.3377 home runs.'

Figure 7. A sample student response

Figure 8 shows the responses given by a weaker student. This student is still able to give a good interpretation of the slope.

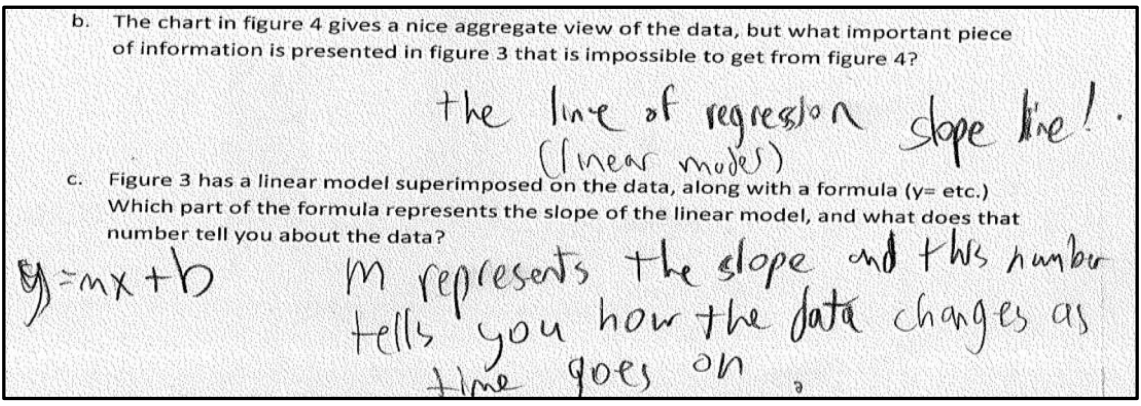

Figure 8. Another sample student response. This weaker student understands slope and can explain it. 


\section{Example from MATH 112, Applied Statistics. Final project}

In statistics, students choose a topic, form a hypothesis, and then gather and analyze data to test that hypothesis. They report their findings both in a paper and in an oral presentation.

Projects included:

- Comparison of yearly temperature means with the crime rate in New York City (using published data).

- Relationship between the day of the week and the number of EMS and fire calls (student was a volunteer at a VFD).

- Cost analysis of several local grocery stores and "supercenters."

This project in particular stresses the goals of being able to draw conclusions from data, communicate those conclusions, and understand and interpret the data that students have gathered themselves. The instructor reports that students (sometimes with considerable help and advice from him) eventually do generally achieve these goals - the culmination of a semester's worth of study and work.

Based on this kind of evidence, we are generally convinced that students enrolled in our QL courses are learning the kinds of things we want them to learn, and that they are becoming more quantitatively literate by completing carefully designed assignments in these courses.

\section{Attitudes survey}

While we are interested in students' mastery of particular knowledge and skills, and in fact those things may be different for different classes, we realized that there was another objective we had not explicitly articulated: We hoped that students' attitudes towards mathematics might change after taking one of our QL courses.

The idea that one can quantify attitudes was a radical one when it was introduced by L.L. Thurstone (1928) early in the twentieth century. But as noted above, it is not uncommon now to try to gauge (changes in) student attitudes during a QL course. One way to measure attitudes towards mathematics is through an anonymous survey. Gold (2006, p. 31) warns,

"While surveys of student attitudes cannot alone assess student learning, giving such surveys early in a course and working on improving students' beliefs about what they must do to succeed in mathematics can affect students' success."

We designed a survey of student attitudes, based on several existing instruments (Fennema and Sherman 1976, Korey 2000), and administered it to students in all sections of MATH 111 and 112 in the fall semester - once at the beginning of the semester and once at the end. Students responded, using a four-point Likert scale, to sixteen statements about their confidence and ability in mathematics ("I earn 
good grades on math tests and quizzes."), their enjoyment of it ("Mathematics is very interesting to me, and I enjoy math courses."), their assessment of its usefulness ("I expect to need mathematical knowledge in my career."), and their reactions to different types of pedagogy ("I enjoy working in groups in class.").

Assigning a score of 4 for Strongly Agree, 3 for Agree, and so forth for positive statements, and revised accordingly for negative statements (indicated by an asterisk), we computed an average score for each question and a total score for the entire survey. The results are summarized in Table 1.

Table 1

MATH 111 Mathematics Attitudes Survey Results: Average Scores

\begin{tabular}{|c|c|c|c|c|}
\hline & $\begin{array}{l}\text { MATH } 111 \\
\text { Pre-Test } \\
(n=65)\end{array}$ & $\begin{array}{l}\text { MATH } 111 \\
\text { Post-Test } \\
(\mathrm{n}=41)\end{array}$ & $\begin{array}{l}\text { MATH } 112 \\
\text { Pre-Test } \\
(n=61)\end{array}$ & $\begin{array}{l}\text { MATH } 112 \\
\text { Post-Test } \\
(\mathrm{n}=48)\end{array}$ \\
\hline $\begin{array}{l}\text { Mathematics is very interesting to me, and I enjoy } \\
\text { math courses. }\end{array}$ & 2.38 & 2.31 & 2.92 & 2.81 \\
\hline $\begin{array}{l}\text { I feel confident in my ability to complete math } \\
\text { problems. }\end{array}$ & 2.80 & 3.02 & 3.00 & 3.02 \\
\hline $\begin{array}{l}\text { I do not feel that I have a good understanding of the } \\
\text { mathematics courses I have taken so far. * }\end{array}$ & 2.84 & 2.51 & 3.00 & 2.76 \\
\hline I earn good grades on math tests and quizzes. & 2.78 & 2.98 & 3.02 & 3.15 \\
\hline $\begin{array}{l}\text { I feel that I have the background knowledge in math } \\
\text { to succeed in this course. }\end{array}$ & 3.09 & 3.19 & 3.25 & 3.10 \\
\hline $\begin{array}{l}\text { Some people will just never "get" math no matter how } \\
\text { hard they try. * }\end{array}$ & 2.58 & 2.57 & 2.64 & 2.54 \\
\hline Technology can make math easier to understand. & 2.83 & 2.73 & 3.15 & 3.17 \\
\hline I enjoy working in groups in class. & 2.97 & 2.98 & 2.75 & 2.62 \\
\hline I believe that mathematics is useful in the real world. & 3.32 & 3.20 & 3.13 & 3.42 \\
\hline When I see a math problem, I get nervous. * & 2.49 & 2.49 & 2.80 & 2.63 \\
\hline If I work hard, I can succeed in math & 3.35 & 3.28 & 3.67 & 3.53 \\
\hline $\begin{array}{l}\text { I expect to need mathematical knowledge in my } \\
\text { career. }\end{array}$ & 2.81 & 2.69 & 3.04 & 3.13 \\
\hline $\begin{array}{l}\text { I am comfortable applying math to real world } \\
\text { situations. }\end{array}$ & 2.83 & 2.98 & 3.17 & 2.98 \\
\hline $\begin{array}{l}\text { In mathematics you can be creative and discover } \\
\text { things for yourself. }\end{array}$ & 2.53 & 2.49 & 2.80 & 2.62 \\
\hline People who are good at math can do math quickly. ${ }^{*}$ & 2.03 & 2.07 & 2.13 & 2.10 \\
\hline $\begin{array}{l}\text { I like exploring problems using real data and } \\
\text { computers. }\end{array}$ & 2.22 & 2.48 & 2.91 & 2.90 \\
\hline TOTAL SCORE & 2.74 & 2.75 & 2.96 & 2.90 \\
\hline CRONBACH'S ALPHA & 0.92 & 0.93 & 0.91 & 0.90 \\
\hline
\end{tabular}

We were disappointed that we did not notice any improvement in students' attitudes towards mathematics after a semester spent in a QL course - and in fact we wondered if we had done more harm than good. There was in fact no discernible difference in responses between pre-and post-test results, or between students in MATH 111 and MATH 112; the slight differences were not statistically significant 
according to a two-sided, paired $t$-test. (We have only aggregate data for each survey, as we did not ask students to identify themselves in any way. That obviously limited our ability to analyze the data. Note, for instance, that several students apparently dropped each course and were not included in the post-survey.) The survey itself is internally consistent, as the Cronbach's alphas exceeded 0.9 in each case.

Improving student attitudes towards mathematics has proven to be elusive. Aiken (1972), in devising his Mathematics Attitude Scale, pointed out that "appreciation and use of mathematics" has been an objective of the National Assessment of Educational Progress (NAEP) from the very beginning. He reported that attitude and achievement in mathematics are generally positively correlated, especially among high school and college students. An analysis of the 1996 NAEP results (Pellegrino et al. 1999) found that the percentage of students who responded positively to statements about attitudes and beliefs about mathematics declined with grade level. Behr (1973), in a study using Aiken's scale, found that gender is also a factor: among first-year liberal arts students at a community college, the correlation between aptitude and achievement in mathematics and interest in the subject was significantly higher for women students.

The reformed teaching practices which we embrace, and whose goals often include improving student attitudes, in fact can have the opposite effect. In a metaanalysis, Smith and Star (2007) reported inconclusive results for students enrolled in several university reform calculus classes. In some studies, student attitudes improved (although perhaps not until several years after the course); in others, attitudes declined. Some students reported less confidence in their computational skills but a more sophisticated understanding of mathematics itself. Researchers at the University of Colorado (Laursen et al. 2014) also found that gender is an important variable: students enrolled in many different mathematics classes taught using inquiry-based learning (IBL) tended to exhibit gains in both interest and confidence in mathematics, while students enrolled in non-IBL classes registered a decline. But the greatest gains were shown by the women students.

Several researchers (Gal and Ginsburg 1994, Evans 2007) have pointed out that students enrolled in introductory statistics classes may have different goals from those enrolled in other introductory mathematics classes, and thus should be assessed differently. Their attitudes towards statistics may in fact be tainted by their previous experiences with mathematics courses.

Those who have reported significant improvements in student attitudes interest in mathematics, a belief in its value or usefulness, enjoyment, confidence have generally achieved that goal by employing some sort of direct intervention. Motivational videos (Hodges and Kim 2013), and encouraging emails (Kim and Keller 2008), for instance, have been found to be helpful in some circumstances. 
In light of all this research, we were ultimately relieved that our students' attitudes appeared to remain fairly stable over the semester, when we had paid little overt attention to improving them. We know we have room for improvement and still hold this as a goal of our QL courses.

\section{What We Have Learned So Far}

We believe that we have learned a fair amount about how well our QL courses address the learning objectives we developed, and that we have learned a great deal about how we want to proceed with assessment in the future.

\section{Are we teaching QL courses?}

Based on instructors' responses, we believe that the courses in the Quantitative Literacy section of the new college core curriculum do indeed exhibit the characteristics of a QL course that we describe in Appendix B. However, we realize we need to gather this information in a less labor-intensive fashion. We have now designed a short form, using a modified 3-point Likert scale (see Appendix C), for instructors to fill out at the end of the semester to provide us with a more manageable amount of information. We hope that this approach will take the instructors less than half an hour to complete and will still give us a good idea of how the courses meet our criteria. The exercise will also remind instructors of the general objectives for the course and the importance of their role in their implementation.

As part of this experience, we were led to think carefully about the role of adjunct faculty in our department, as they often teach these general education courses. We want to respect their experience and insights, while also respecting their time and energy. Our advice for others who wish to begin assessing a general QL requirement is to involve as many stake-holders as possible in the process. Anyone who teaches such a course should be included in developing goals and objectives, assessment instruments, and course syllabi, as well as in assessing the course outcomes. This is a way to show adjunct faculty, especially, that they are valued and are part of the community.

It is also important to talk to faculty in other departments who are teaching QL courses; their disciplines are undoubtedly addressing quantitative literacy issues. If possible, try to synchronize learning objectives and topics covered, as students may move from department to department in fulfilling requirements. Above all, be prepared to revise - the goals, the instruction, and the assessment - as part of the assessment cycle. 


\section{Are we satisfied with our goals for a QL course? Are students meeting our goals?}

Again, based on examples of student work submitted by instructors, we believe we are doing a good job of creating assignments that address the five learning objectives we articulated for QL courses. For the most part, students are meeting those objectives. However, we may want to revisit that list of objectives; for example, should we include a separate objective that specifically mentions technology?

How should we decide when we have done a good job? How many students earning a grade of $80 \%$ on an assignment would make us happy? When is $70 \%$ okay? Is there a difference between proficient and exemplary performance? We will discuss these questions and set more reasonable goals and data-collection methods for our classes.

We need to do a better job of letting instructors know, early on, what sort of assessment questions we are going to ask them at the end of the semester, and what sort of documentation they should be saving. In fact, we should involve them in these decisions. We need a clear, streamlined process for all faculty to assess the effectiveness of their courses and to report their results. We could also share appropriate assignments - via a website, for instance.

\section{What about student attitudes?}

Should we add yet another QL goal to our list, one that specifically addresses student attitudes - towards mathematics, or working with data, or using technology, or collaborative learning? The literature suggests that student attitudes toward learning are important; can we change them in a positive direction in one course?

A colleague from another institution suggested that perhaps students were put off by the term "mathematics" in the survey; perhaps we should have used a term less fraught with anxiety, like "quantitative skills" or "working with data." Perhaps one semester was too short a time to effect much real change in attitude; while some researchers (Everingham et al. 2013; Van Perusem et al. 2012) report substantive change in attitudes during the course of one college course, others, as noted above, have not. We will use what we have learned from the research literature to inform our decisions.

We could use a different sort of assessment for the attitudes survey. At the very least, in the future we will use an electronic, rather than paper-and-pencil instrument, making life easier and less error prone both for students and faculty and for our poor student worker who tabulated all the results. We will try to interview a few students to explore their reactions to the survey itself and whether they would have responded differently to a different kind of assessment tool. 
The next time we administer such a survey, we will think carefully about rewriting the statements to avoid asking about "math," especially for the courses that are not taught in the Department of Mathematics. We hope to find a way to survey students several semesters after taking this first QL course, to see if benefits are felt later in a student's career. We will discuss our implicit goals with the instructors of QL courses before designing another survey - or choosing another assessment instrument.

\section{Plans for the Future}

Now that we have been through one cycle of testing our ideas about assessment, we have a much better idea about what we want to do with our courses, and with assessing them, as the QL requirement has become an official part of the core curriculum.

We are still interested, of course, in how the various courses in this section of the core curriculum choose to address the characteristics of quantitative literacy. We feel that we have a good idea of how courses in our own department meet those criteria; now we need to share our findings and start collecting data with faculty in other departments.

During the assessment process, we realized that we had two implicit goals that students would learn to use technology to analyze and interpret data, and that they would gain confidence in and an appreciation for mathematics by taking a QL course. We must decide whether to include these objectives in the formal list of student learning outcomes.

A pipe dream: Ideally, we want to know which of these skills students retain upon graduation; how could/should we assess that? Would our college support a graduation exit survey or instrument of some sort?

From reading the QL literature and attending professional conferences and sharing ideas with colleagues, we have learned about others' efforts in this area. Some ideas we find especially appealing: In addition to the assessments described above, we plan to create and implement an objective assessment like the ones found in Madison et al. (2008). This type of assessment asks students to interpret an article, graph, or table of data; the same assessment will be used across all QL courses so that we can assess the QL part of the core curriculum as a whole. We believe that, as Grawe (2011) described, carefully stating our learning objectives and consciously teaching to them will benefit our students. And we are intrigued by the prompt-less assessments described in Boersma and Klyve (2013) for measuring students' habits of mind and would like to learn more about them. (Just because students know how to use QL skills, do they actually use them when not explicitly prompted to do so?)

We are heartened by our first experiences with assessing QL and look forward to continuing the process in the future. We will continue to refine our description 
of "how to recognize a QL course," the general learning objectives for all QL courses at our college, and the assessment instruments we use to measure our success. This experience has provided us with a way to discuss an important topic with many people, including faculty in other departments or in part-time positions, and colleagues at other institutions. It promises to be a rich area for learning more about teaching and learning and for sharing our results with others.

\section{References}

Aiken, L. R., Jr. 1972. Research on attitudes toward mathematics. The Arithmetic Teacher 19 (3): 229-234.

Behr, A. N. 1973. Achievement, aptitude and attitude in mathematics. The TwoYear College Mathematics Journal 4 (2): 72-74. http://dx.doi.org/10.2307/3026447

Boersma, S., and D. Klyve. 2013. Measuring habits of mind: Toward a promptless instrument for assessing quantitative literacy. Numeracy 6 (1): Article 6. http://dx.doi.org/10.5038/1936-4660.6.1.6 (accessed April 9, 2014).

Chance, B. L., and A. J. Rossman. 2014. Investigating statistical concepts, applications, and methods, $2^{\text {nd }} e d$. (ISCAM II). http://www.rossmanchance.com/iscam2/index.html (accessed August 15, 2014).

Evans, B. 2007. Student attitudes, conceptions, and achievement in introductory undergraduate college statistics. The Mathematics Educator 17 (2): 24-30.

Everingham, Y., E. Gyuris, and J. Sexton. 2013. Using student feedback to improve student attitudes and mathematical confidence in a first year interdisciplinary quantitative course: from the ashes of disaster! International Journal of Mathematical Education in Science and Technology 44 (6): 877892. http://dx.doi.org/10.1080/0020739X.2013.810786

Fennema, E., and J. A. Sherman. 1976. Fennema-Sherman mathematics attitudes scales: Instruments designed to measure attitudes toward the learning of mathematics by males and females. Catalog of Selected Documents in Psychology, 6 (1): 31. http://dx.doi.org/10.2307/748467

Gal, I., and L. Ginsburg. 1994. The role of beliefs and attitudes in learning statistics: Towards an assessment framework. Journal of Statistics Education 2 (2). http://www.amstat.org/publications/jse/v2n2/gal.html (accessed January 1, 2015).

Gold, B. 2006. Assessment of developmental, quantitative literacy, and precalculus programs. In Steen 2006, 29-35. 
Grawe, N. 2011. Beyond math skills: Measuring quantitative reasoning in context. New Directions for Institutional Research 149: 41-52. http://dx.doi.org/10.1002/ir.379 (accessed April 15, 2014).

Gillman, R. 2011. SIGMAA on Quantitative Literacy: Introduction. Mathematical Association of America. http://sigmaa.maa.org/q1/about.php (accessed April 14, 2014).

Hodges, C. B., and C. Kim. 2013. Improving college students' attitudes toward mathematics. TechTrends 57 (4): 59-65. http://dx.doi.org/10.1007/s11528013-0679-4

Howard, J. 2013. Teaching quantitative reasoning: What's working at U-M? University of Michigan Center for Research on Learning and Teaching blog. http://www.crlt.umich.edu/node/1010 (accessed May 26, 2015).

Kim, C., and J.M. Keller. 2008. Effects of motivational and volitional email messages (MVEM) with personal messages on undergraduate students' motivation, study habits and achievement. British Journal of Educational Technology 39 (1): 36-51.

Korey, J. 2000. Dartmouth College Across the Curriculum Evaluation Summary: Mathematics and Humanities Courses. http://www.math.dartmouth.edu/ matc/Evaluation/humeval.pdf (accessed April 15, 2014).

Laursen, S. L., M.-L. Hassi, M. Kogan, and T.J. Weston. 2014. Benefits for women and men of inquiry-based learning in college mathematics: A multiinstitution study. Journal for Research in Mathematics Education 45 (4): 406-418. http://dx.doi.org/10.5951/jresematheduc.45.4.0406

Lehrer, J. 2011. Cracking the scratch lottery code. Wired Magazine 19.02. http://www.wired.com/2011/01/ff_lottery/ (accessed August 27, 2014).

Madison, B. L., S. Boersma, C. L. Diefenderfer, and S. W. Dingman, 2008. Case studies for quantitative reasoning: A casebook of media articles. New York, NY: Pearson.

Malkevitch, J., L. M. Lesser, A. D. Taylor, B. P. Conrad, and S. J. Brams. 2011. For all practical purposes: Mathematical literacy in today's world, $9^{\text {th }} \mathrm{ed}$. New York, NY: W. H. Freeman.

National Council of Teachers of Mathematics. 2000. Principles and standards for school mathematics. Reston, VA: NCTM.

National Numeracy Network. 2013. What is Numeracy/QL/QR? http://serc.carleton.edu/nnn/resources/index.html (accessed April 15, 2014).

Pellegrino, J.W., L.R. Jones, and K.J. Mitchell, eds. 1999. Grading the nation's report card: Evaluating NAEP and transforming the assessment of educational progress. Washington, D.C.: National Academies Press. 
Rossman, A.J., and B.L. Chance. 2012. Workshop statistics: Discovery with data, $4^{\text {th }} e d$. Hoboken, NJ: John Wiley and Sons.

Sikorskii, A., V. Melfi, D. Gilliland, J. Kaplan, and S. Ahn. 2011. Quantitative literacy at Michigan State University, 1: Development and initial evaluation of the assessment," Numeracy 4 (2): Article 5. http://dx.doi.org/10.5038/1936-4660.4.2.5

Smith, J.P. III, and J.R. Star. 2007. Expanding the notion of impact of K-12 standards-based mathematics and reform calculus reform programs. Journal for Research in Mathematics Education 38 (1): 3-34.

Sons, L., R. L. Bernhardt, D. Bushaw, W. G. Chinn, L. Curnutt, P. C. Curtis, Jr., J. Donaldson, B. H. Edwards, E. Z. Falconer, J. Ferrini-Mundy, S. Garfunkel, R. Gillman, J. G. Harvey, R. E. Hill, E. T. Hoefer, B. A. Jur, D. Kletzing, M. M. Neff, R. Northcutt, K. O'Hara, and J. L. Solomon. 1996. Quantitative reasoning for college graduates: A complement to the standards. Washington, DC: Mathematical Association of America.

Steen, L.A., ed. 2001. Mathematics and democracy: The case for quantitative literacy. Princeton, NJ: The National Council on Education and the Disciplines.

- 2004. Achieving quantitative literacy: An urgent challenge for higher education. Washington D.C.: The Mathematical Association of America.

— ed., 2006. Supporting assessment in undergraduate mathematics. Washington DC: The Mathematical Association of America. http://www.maa.org/publications/ebooks/supporting-assessment-inundergraduate-mathematics

Strand, K. J., and M. E. Mayfield. 2002. Pedagogical reform and college women's persistence in mathematics. Journal of Women and Minorities in Science and Engineering 8 (1): 50-59. http://dx.doi.org/10.1615/JWomenMinorScienEng.v8.i1.50

Thurstone, L. L. 1928. Attitudes can be measured. American Journal of Sociology 33: 529-554. http://dx.doi.org/10.1086/214483

Vacher, H. L., and D. Wallace. 2013. The scope of Numeracy after five years. Numeracy 6 (1): Article 1. http://dx.doi.org/10.5038/1936-4660.6.1.1

Van Peursem, D., C. Keller, D. Pietrzak, C. Wagner, and C. Bennett. 2012. A comparison of performance and attitudes between students enrolled in college algebra vs. quantitative literacy. Mathematics and Computer Education 46 (2): 107-118.

Ward, R. M., M. C. Schneider, and J. D. Kiper. 2011. Development of an assessment of quantitative literacy at Miami University. Numeracy 4 (2): Article 4. http://dx.doi.org/10.5038/1936-4660.4.2.4 
Wright, M. C. and J.E. Howard. 2015. Assessment for improvement: Two models for assessing a large quantitative reasoning requirement. Numeracy 8 (1):

Article 6. http://dx.doi.org/10.5038/1936-4660.8.1.6

\section{Appendix A: Course Descriptions}

\section{Courses designed as general education courses}

- MATH 111 Mathematics Everywhere

This is an umbrella course, with several different versions. The Catalog description: These courses promote students' understanding and appreciation of mathematics and develop quantitative and problem solving skills. Each course uses the computer to aid in exploration and computation. Various topics are offered each semester.

- MATH 111A The Mathematics of Daily Life

This course introduces students to a wide range of applications of mathematics to modern life. Students will learn some surprisingly simple mathematical ideas that are fundamental in the working of the modern world. Among the topics of the course are: the mathematical tools that businesses use to schedule and plan efficiently; the number codes such as UPC, ZIP codes, and ISBN codes that help organize our lives; and the surprising paradoxes and complexities of elections. [This course is based on the For All Practical Purposes text (Malkevitch et al. 2011.]

- MATH 111B The Mathematics of Democracy

Students in this course will study two basic questions about democracy -"How do we vote?" and "How do we allocate power?" - from a mathematical perspective. The mathematics reveals surprising paradoxes and complications in the answers to these questions. The course explores why we vote the way we do, what problems arise in voting, and what alternatives are being tried. It will also consider how we can divide the riches of society fairly - and even what the word "fairness" could possibly mean. 
- MATH 111G The Mathematics of Games and Sports

This course examines the serious mathematics of fun. How often should one expect to see a perfect game in Major League Baseball? Why should you always split $8 \mathrm{~s}$ in blackjack? How can a tournament among seven teams best be scheduled? Will women ever be faster than men in the highest levels of track performance? Is it better to bet on a color or a number in roulette? Students will explore all of these questions and more using mathematical tools such as probability, linear models, and graph theory. This class also uses computational tools to solve problems and analyze data.

\section{Statistics courses}

- MATH 112 Applied Statistics

Statistics with emphasis on applications. Topics covered include statistical measures, normal distribution, sampling theory, statistical inference, hypothesis testing and quality control, correlation, regression and analysis of variance. Students will use statistical software packages on the computer to explore topics in more depth.

Together with its newer cousin ...

- MATH 112W Workshop Statistics

An active-learning approach to introductory statistics. Emphasis is on collaboration, discovery, exploration, use of technology. Topics covered are the same as those in MATH 112: statistical measures, distributions, sampling, inference, confidence intervals, correlation, regression, analysis of variance. Students will use a statistical software package. [This course is based on the Rossman \& Chance text (2011) of the same name.]

... and a new basic statistics course designed for math and science majors:

- MATH 213 Statistical Concepts and Methods

An introduction to the practice of statistics, its applications, and its mathematical underpinnings. Focus is on data, activities, technology, conceptual understanding. This course is intended for mathematics and science majors. [This course is based on the ISCAM text (2014), also by Chance \& Rossman.] 
- ECON/MANAGEMENT 212 Statistics for Economics and Management

This course is an introductory course in statistics for economics and management students. Students will be introduced to descriptive statistics, probability, discrete and continuous probability distributions, correlations and linear regressions. Completing this course will give the student a solid grounding in statistics that is necessary to successfully complete upper level economics and management courses.

- PSYCHOLOGY 211 Elementary Statistics

Statistical methods, including frequency distributions and graphing, averages, measures of variability and correlation, t-tests, analysis of variance and several distribution-free tests. Examples are drawn from the social, behavioral and biological sciences.

- SOCIOLOGY 261 Quantitative Methods for the Social Sciences

An introduction to the methods used to analyze and interpret quantitative social science data with an applied focus. Topics include using Statistical Package for the Social Sciences, locating and downloading data sets from the internet, reading and interpreting quantitative social science research reports (including surveys, evaluation research, and observational and experimental designs), and the effective communication of quantitative results in written and visual forms. Some attention is also given to descriptive statistics and measures of central tendency, hypothesis testing, the logic of inferential statistics, and choosing the appropriate statistical application for a given research problem.

\section{Calculus}

- MATH 201 Workshop Calculus I

Relationships, functions, rates of change, initial value problems, derivatives of functions of one variable, numerical solutions, applications. Emphasis is on problem solving, collaborative work, computer exploration, writing. 


\section{Appendix B: How to Recognize a QL Course ${ }^{6}$}

(We distributed this list to faculty on the Core Curriculum Committee and to those teaching newly-designated QL courses.)

We believe that a course that satisfies the QL requirement should include many of the following:

- Problem-solving: applying mathematics to real-world problems.

- Working with data.

- Using (and knowing when to use) appropriate technology.

- Looking carefully at quantitative arguments in the media, or in journal articles in another discipline.

- Reasoning: using quantitative skills to defend one's opinion.

- Solving multi-step quantitative problems (as in a class project).

- Active learning and engagement.

- Collaborative learning.

- Communicating (mostly in writing) about quantitative issues in everyday life. May include homework, exams, lab reports, essays.

- Presenting data in useful ways: graphs, charts, tables, equations.

- Multiple forms of assessment.

${ }^{6}$ The QL literature includes many references that support the compilation of a list such as this one. See, for example, Ward et al. (2011), Sikorskii et al. (2011), Howard (2013), Wright and Howard (2015), and other papers in this journal (for a bibliographic guide, see Vacher and Wallace 2013). 


\section{Appendix C: Assessing the characteristics of a QL course}

Please fill out the questionnaire below for the QL course you taught this semester. This exercise should take less than 30 minutes. Thanks!

Name

Semester

Course

Please indicate, by checking in the boxes below, the extent to which you believe this course incorporated the following characteristics:

\begin{tabular}{|l|l|l|l|}
\hline Characteristic & $\begin{array}{l}\text { None or not } \\
\text { much }\end{array}$ & $\begin{array}{l}\text { A moderate } \\
\text { amount }\end{array}$ & A lot \\
\hline $\begin{array}{l}\text { Problem-solving: applying mathematics to real- } \\
\text { world problems. }\end{array}$ & & & \\
\hline Working with data. & & & \\
\hline $\begin{array}{l}\text { Using (and knowing when to use) appropriate } \\
\text { technology. }\end{array}$ & & & \\
\hline $\begin{array}{l}\text { Looking carefully at quantitative arguments in the } \\
\text { media, or in journal articles in another discipline. }\end{array}$ & & & \\
\hline $\begin{array}{l}\text { Reasoning: using quantitative skills to defend } \\
\text { one's opinion. }\end{array}$ & & & \\
\hline $\begin{array}{l}\text { Solving multi-step quantitative problems (as in a } \\
\text { class project). }\end{array}$ & & & \\
\hline Active learning and engagement. & & & \\
\hline Collaborative learning. & & & \\
\hline $\begin{array}{l}\text { Communicating (mostly in writing) about } \\
\text { quantitative issues in everyday life. May include } \\
\text { homework, exams, lab reports, essays. }\end{array}$ & & & \\
\hline $\begin{array}{l}\text { Presenting data in useful ways: graphs, charts, } \\
\text { tables, equations. }\end{array}$ & & & \\
\hline Multiple forms of assessment. & & & \\
\hline
\end{tabular}

Please choose two of the characteristics which you indicated that your course exhibited "a lot" and write a brief paragraph about how you addressed them. Include samples of student work if appropriate. 